\title{
Evaluation and Management Outcomes and Burdens in Patients with Refractory Chronic Cough Referred for Behavioral Cough Suppression Therapy
}

\section{Laurie Slovarp ( $\sim$ Laurie.Slovarp@umontana.edu )}

Universityo f Montana https://orcid.org/0000-0002-3547-4092

\section{Marie Jette}

University of Colorado Anschutz Medical Campus: University of Colorado - Anschutz Medical Campus Amanda Gillespie

Emory University School of Medicine

Jane Reynolds

University of Montana Missoula

Julie Barkmeier-Kraemer

University of Utah

\section{Research Article}

Keywords: chronic cough, refractory chronic cough (RCC), speech-language-pathology (SLP), behavioral cough suppression therapy (BCST), cost-effectiveness

Posted Date: February 19th, 2021

DOI: https://doi.org/10.21203/rs.3.rs-205835/v1

License: (c) (1) This work is licensed under a Creative Commons Attribution 4.0 International License.

Read Full License

Version of Record: A version of this preprint was published at Lung on April 5th, 2021. See the published version at https://doi.org/10.1007/s00408-021-00442-w. 


\section{Abstract}

Purpose: The purpose of this study was to investigate the typical symptoms and medical management characteristics of adult patients with refractory chronic cough (RCC) who are referred to speech-language pathology (SLP) for behavioral cough suppression therapy (BCST) in order to estimate cost-effectiveness and efficiency of current practice patterns for this population.

Methods: One hundred fifty-nine (159) patients with RCC referred for BCST were surveyed. Patients completed an initial survey at BCST onset related to symptom pattern and prior treatment, including the Leicester Cough Questionnaire (LCQ). Every 4-6 weeks patients completed follow-up surveys to assess their response to BCST.

Results: Mean age was 58 years (83\% women). The majority of participants reported their cough began two or more years prior to BCST. Approximately half reported seeing four or more physicians (49\%) and being prescribed four or more medications (55\%) prior to BCST. Medications targeting post-nasal drip (71\%), reflux (70\%), asthma (56\%), and allergies (56\%) were most commonly prescribed. BCST resulted in a clinically significant improvement in 113 (70.1\%) participants. The mean change in LCQ for those who improved with BCST was 6.61 . Over half $(58 \%)$ reported they were quite satisfied to completely satisfied with their treatment response. The average time from enrollment to study completion was 64 days.

Conclusion: The results of this study suggest early intervention with BCST may be a more cost-effective and efficient option for patients with RCC.

\section{Background}

Chronic cough, defined as cough lasting more than eight weeks, is highly prevalent [1] disabling [2], and carries substantial economic burden. The multifactorial nature of chronic cough frequently does not allow identification of a single etiologic mechanism for the cough [3]. As such, patients are typically evaluated with a multitude of tests and treated by numerous healthcare professionals including primary care physicians and subspecialists in pulmonology, allergy, otolaryngology, gastroenterology, and speechlanguage pathology. The goal of evaluation across various disciplines is to determine an individual's specific chronic cough phenotype, the most common of which are upper airway cough syndrome (commonly referred to as post-nasal drip syndrome), cough-variant asthma, gastroesophageal reflux (GERD), and eosinophilic bronchitis [4, 5]. When each of these has been evaluated and found to be absent or adequately treated yet symptoms persist, a patient is considered to have refractory chronic cough (RCC). Evaluation for utility of behavioral cough suppression therapy (BCST) -- also referred to in the literature as cough control therapy, cough suppression therapy, Physiotherapy and Speech-Language Therapy Intervention, among other similar variations [6-8] - typically occurs after completion of empiric treatment and testing for these common cough phenotypes [9-12].

BCST is administered by speech-language pathologists (SLP) sub-specialized in disorders of the larynx and upper airway. The goal of BCST is to use cognitive-behavioral techniques to override the cough reflex 
and, by so doing, improve cough control and reduce cough sensitivity. There is moderate evidence supporting its efficacy for improving quality of life, reducing cough severity and frequency, and decreasing cough sensitivity in patients with RCC $[8,13-15]$. BCST is safe, improves cough outcomes in up to $87 \%$ of patients, is inexpensive and efficient (i.e., patients typically need no more than four treatment sessions with improvement seen as soon as one week following onset of therapy) [16]. As such, a trial of BCST may be more cost-effective than, and as effective as, other common empiric medical treatments for RCC.

This study describes survey data from 159 patients who underwent BCST and outlines their treatment course and quality of life outcomes. Based on these data, we propose a treatment paradigm for RCC that implements BCST as an early treatment after serious conditions have been ruled out. Such a paradigm does not obviate the need for other testing or medication trials; however, early implementation may offer improvements in quality of life and reduce overall economic and life burdens resulting from this disabling condition.

\section{Methods}

This survey study was approved by the University of Montana Institutional Review Board on March 05, 2015 (IRB\#: 242-14). The data reported herein describes a subset of data gathered in a larger ongoing study looking at symptom and treatment patterns of patients with RCC. The current study pertains to treatment patterns and response to treatment specifically in patients with RCC treated with BCST. Data used in this paper were collected from June 2015 to June 2020.

\section{Setting and Participants.}

All data were collected via Health Insurance Portability and Accountability Act (HIPAA) -compliant Qualtrics survey software or a paper form. Participants were recruited by SLPs who regularly provide BCST. Participating SLPs were from thirteen clinics across six different states in the United States and one hospital clinic in Australia. All participants were referred to a participating SLP for BCST, were at least 18 years old, had a complaint of cough for at least the past eight weeks, were not current smokers, did not have a formal pulmonary diagnosis (e.g. chronic obstructive pulmonary disease, asthma confirmed with objective testing), and had not taken an ACE-inhibitor medication within two months of enrollment.

\section{Procedures}

Survey Development. The survey consisted of four parts: 1 ) relevant medical history (e.g., history of smoking), 2) patient-reported symptoms, 3) questions related to prior treatment, and 4) the Leicester Cough Questionnaire (LCQ) $[17,18]$. Due to an oversight, the initial survey was missing one question ("How many physicians have you seen for your cough?"). This question was added after the first 38 respondents. Given the primary purpose of this paper is to describe treatment patterns in patients with 
RCC who are referred for BCST, we report only the results related to relevant medical history, prior treatment, and response to BCST. This portion of the survey can be viewed in Appendix A.

Survey administration. SLPs at each participating clinic identified potential participants based on a primary complaint of cough and satisfaction of inclusion criteria. Clinics were given three options to recruit potential participants - an electronic tablet, a paper form with self-addressed and stamped envelope, or a recruitment flyer that contained a web address, a QR code, and a phone number that allowed patients to enroll on their own time. The majority of clinics opted for paper forms or flyers. All participants completed the survey within one day of completing their BCST evaluation session.

Following enrollment, participants were contacted by mail, phone, text, and/or e-mail, depending on their indicated preference, every four to six weeks to monitor success of BCST. The follow-up survey consisted of the LCQ and questions related to adherence, and their overall satisfaction with their cough status on a scale from 1 (Not at all satisfied. I'm not any better) to 7 (Completely satisfied. My cough is gone). Followup data continued to be gathered every four to six weeks until the participants reported a satisfaction of at least 5 (Quite satisfied, I'm quite a bit better), or until they were no longer making progress or no longer wished to participate in the study.

\section{Data Analysis}

Data analysis was performed with Statistical Package for the Social Sciences (SPSS) version 26 software. The paired t-test was used to determine significance of change pre-and post-BCST. Spearman's correlation was used to determine the association between perceived treatment satisfaction and the LCQ. Alpha was set at 0.05 .

\section{Results}

A total of 211 patients referred for BCST completed the enrollment survey. Of these, 164 completed follow-up surveys, five of whom were discarded due to incongruent data (i.e., LCQ showing improvement but reporting BCST did not help). This left a sample size of 159 .

\section{Demographics}

One hundred thirty-two (83\%) of the respondents identified as female. Mean age of the sample was 58. The majority identified as either Caucasian (66\%) or unknown/do not want to report (29\%). Demographic data, including age by decade, are presented in Table 1 .

\section{Relevant Medical History}

Smoking. Thirty-three $(21 \%)$ respondents reported a history of smoking, $27(82 \%)$ of whom quit smoking over 10 years prior. Eighteen of the 33 who smoked (55\%), smoked 10 years or fewer (Table 1 ). 
Cough Length andPrior Treatment. Length of cough was asked in a multiple-choice format with the longest option being "over 2 years", which was the most common answer with 83 (52\%) of the respondents. Only 28 (18\%) reported a cough duration of six months or less (see Table 1). One hundred twenty-two (122) respondents reported number of physicians seen. The remaining left the question blank, reported they did not recall, or reported "too many to count". Of the 122 who answered the question, $49 \%$ reported seeing four or more physicians prior to BCST. Only $12 \%$ reported seeing one physician, while $15 \%$ saw two physicians, and $23 \%$ saw three physicians. Fifty five percent (55\%) of respondents reported being prescribed four or more medications prior to BCST. Over half reported being prescribed medications for post nasal drip (71\%), reflux (70\%), asthma (56\%), and allergies (56\%). Distribution of number of physicians seen and prescribed medications are depicted in Figures 1 and 2.

\section{Response to BCST}

Mean total LCQ scores pre and post BCST were 11.29 and 15.95, respectively, a statistically significant increase of $4.66(95 \% \mathrm{Cl} 4.02$ to 5.30$), t(158)=14.39, p<.0005, d=1.14$. Each LCQ domain score also significantly improved ( $p<.0005$ for each) and can be viewed in Table 2 .

A conservative threshold of change in total LCQ score of at least 2.0 was set to indicate a clinically relevant improvement in cough, which is 0.7 points higher than the "minimum important difference" reported in the literature[19]. One hundred thirteen (70.1\%) of the 159 respondents met this threshold. The mean change in LCQ for these 113 respondents far exceeded the 2.0 threshold at 6.61 , resulting in a mean total LCQ score following BCST for these individuals of 17.74 out of a total possible score of 21. Mean compliance in those who improved with BCST was .16 points higher than in those who did not improve; however, this difference was not statistically significant as tested with an independent t-test $(95 \% \mathrm{Cl},-.483$ to .163$), \mathrm{t}(135)=-.979, \mathrm{p}=.329$.

There was a strong positive correlation between patients' perception of improvement and total LCQ scores, $r_{s}(128)=.742, p<.0005$. Less than $20 \%$ of the entire sample reported no improvement $(11 \%)$ or hardly any improvement (6\%). Fifty eight percent (58\%) reported they were quite satisfied $(22.3 \%)$, very satisfied $(23.1 \%)$, or completely satisfied $(12.3 \%)$. Full distribution of satisfaction scores is shown in Figure 3.

Number of BCST sessions was not collected; however, the mean number of days between enrollment and final follow-up survey was 64 . Given follow-up data requests were sent every 4-6 weeks until participants either reported a satisfaction score of at least 5 (i.e., quite-a-bit satisfied, I'm quite-a-bit better), or were no longer showing progress, the data suggests the majority of participants who improved with BCST did so within 5-9 weeks. LCQ and mean days from enrollment to final follow-up are presented in Table 3.

\section{Discussion}

This prospective study of 159 patients with RCC adds to the growing body of literature highlighting the management difficulties of this disorder. Most patients in this investigation reported seeking care for their 
cough from at least four physicians, and trialing at least six different medications intended to treat cough before enrolling in BCST. At the time of enrollment in BCST, patients were still symptomatic, with low LCQ scores, indicating their cough negatively impacted quality of life. Following BCST, the total LCQ score increased on average over 4.6 points, indicating a significant and clinically meaningful improvement. Given the majority of participants included in this study reported having been prescribed four or more ineffective medications prior to BCST, these data suggest that BCST is at least as effective as some medical intervention for cough in the sample studied here. Given the average wait time to see a physician in the United States is approximately 24 days[20] and the most commonly prescribed empiric treatments for RCC (i.e., pharmaceutical treatments for rhinitis, GERD, or asthma) require a one-to-six-month trial period to determine effectiveness [21], the health and financial burden of such a protracted time to symptom resolution is significant.

Pharmaceutical treatments directly targeting cough hypersensitivity have been shown to be helpful in a proportion of patients with RCC; however, the data presented here suggests BCST is at least as, or more, effective, and with a much lower risk profile. Ryan et al. (2012) [22] is one of the few neuromodulator efficacy studies to include the LCQ as an outcome measure, allowing for direct cross-study comparison. Their placebo-controlled trial showed a mean change in LCQ of 2.5, which is nearly 2 full points lower than the mean LCQ change of 4.66 in the current study. Furthermore, $31 \%$ of the participants in Ryan et al.'s study experienced negative side effects. Our data also shows BCST to be superior to low dose morphine, which has been shown to reduce symptoms in approximately half of patients with RCC [8] with an average change in LCQ of 3.2.

The 2020 Medicare charge[23] for the most commonly prescribed tests for patients with RCC (i.e., chest $\mathrm{CT}$, sinus $\mathrm{CT}$, laryngoscopy, pulmonary function testing, allergy testing, swallow study, $\mathrm{pH}$ reflux testing) totals over $\$ 1200$. With the average initial visit charge being $\$ 110$, and the patients in this sample seeing on average at least 4 different physicians, $\$ 440$ is spent on initial physician visits alone, totally over $\$ 1500$ in tests and physician charges without counting the cost of repeat physician visits or medications (see Table 4). Conversely, the cost of one session of BCST is $\$ 81.20$. Although we did not collect data on number of BCST sessions, prior studies indicate patients undergoing BCST typically receive no more than four sessions, for a total cost of $\$ 417.19$. Further, and perhaps most importantly, these patients completed BCST afterfailing medical therapies, and only after BCST did they experience a meaningful improvement. Nearly $60 \%$ reported high satisfaction and symptom resolution with BCST, $29 \%$ of whom reported their cough was nearly or completely gone.

Results of the current investigation support past BCST efficacy literature. In 1988, Blager [24] reported on four patients with refractory cough of presumed psychogenic origin. One patient underwent BCST with symptom resolution and cessation of cough suppression medications. In 2006, Vertigan and colleagues [25] published a prospective randomized placebo-controlled trial of four sessions of BCST $(n=47)$ compared to healthy lifestyle education training $(n=50)$. Eighty-eight percent of participants in the intervention group achieved a significant reduction in cough, compared to only $14 \%$ in the placebo group. Like participants in the current study, those in the Vertigan investigation underwent multiple diagnostic 
tests and medication trials prior to initiation of BCST. In 2017, Chamberlain Mitchell and colleagues [26] reported an improvement in LCQ of 3.4 in 34 patients following four sessions of BCST compared to improvement of only 1.53 in 41 control patients. Like the Vertigan study and ours, these patients had failed common empiric treatments prior to enrolling in BCST. Patients in the current study improved an average of 3.2 points more on the LCQ than the intervention group in the Chamberlain Mitchell investigation, adding further evidence to the strong efficacy of BCST. Taken together, the extant literature and the current investigation demonstrate that BCST is efficacious at reducing or eliminating cough, and cost-effective when compared to empiric medical treatments. Further, BCST can be initiated at any time in the diagnostic process without sacrificing accuracy of other diagnostic tests or empiric treatments. For example, patients could be offered BCST concurrently with empiric treatment for GERD, assuming they also have peptic symptoms (see, European Respiratory Guidelines [8]), which requires at least four weeks of medical management before symptom change [27].

The results of this survey highlight the need for several areas of future investigation. Randomized controlled trials would be beneficial for determining the role of first-line medical and behavioral and combined medical/behavioral therapies in improving objective measures of cough and quality-of-life. Based on the present data, we suggest consideration of early intervention with BCST is potentially more cost-effective and efficient for treating RCC than the conventional treatment model. An example of early intervention is offering BCST to a patient who visits their primary care physician because they have been coughing for eight weeks following a resolved upper respiratory tract infection. Current standard of care is to first evaluate for red flags and obtain a chest x-ray, then prescribe empiric trials of proton pump inhibitors, inhalers, and/or nasal sprays, and finally refer to a pulmonologist and/or otolaryngologist if symptoms persist[28]. Future care could involve initiation of BCST at the time of empiric treatment. In some cases, early initiation of BCST might even expedite appropriate evaluation by specialists, as experienced SLPs with training in laryngeal and upper airway disorders may be able to recognize features of RCC that are consistent with more concerning pathologies (i.e., subglottic stenosis, tracheobronchomalacia, vocal fold lesions).

\section{Conclusion}

The majority of patients that underwent BCST for RCC in this study experienced an improvement in their cough and quality-of-life in spite of previous extensive medical work up and treatment, suggesting that early intervention with BCST may be a more cost-effective and efficient option for patients with RCC.

\section{Abbreviations}

behavioral cough suppression therapy (BCST)

gastroesophageal reflux disease (GERD)

institutional review board (IRB) 
Leicester Cough Questionnaire (LCQ)

refractory chronic cough (RCC)

speech-language pathologists (SLP)

\section{Declarations}

Funding: Mountain West Clinical Translational Infrastructure Network through a grant from the National Institute of General Medical Sciences of the National Institutes of Health: \#: 1U54GM104944.

Conflict of interest/Competing interests: The authors declare no conflicts of interest associated with this submission.

Availability of data and material: The first author holds all data and materials, which can be made available upon request.

Code Availability: not applicable

Ethics approval: This research was approved by the University of Montana Institutional Review Board March 05, 2015 (IRB\#: 242-14)

Consent to participate: All subjects gave consent to participate in this research prior to completing the survey.

Consent for publication: All authors give consent for publication

\section{Acknowledgements}

The authors would like to thank the following for their assistance with recruitment for this study: Lynn Harris, MS, CCC-SLP, Carol Cady, MD, Jennifer Andrus, MD, Peter Belafsky, MD, Krishna Sundar, MD, Eric Stern, MD, Megan Walker, MS, CCC-SLP, Lisa D'Oyley, MS, CCC-SLP Jennifer Spielman, MA, CCC-SLP, Anne Vertigan, PhD, Joy Hesse, MA, CCC-SLP, Mary Spremulli, MA, CCC-SLP, Kristie Miner, SLP, Karen Cox, SLP, Michele Payton Marsh, SLP. The authors also acknowledge the following students who were instrumental in collecting and collating the data: Emma Bozarth, Sarah Popp. This research was funded by the Mountain West Clinical Translational Infrastructure Network through a grant from the National Institute of General Medical Sciences of the National Institutes of Health: \#: 1U54GM104944.

\section{References}

1. Song WJ, Chang YS, Faruqi S, Kim JY, Kang MG, Kim S, et al. The global epidemiology of chronic cough in adults: a systematic review and meta-analysis. Eur Respir J. 2015;45(5):1479-81. doi: 10.1183/09031936.00218714. 
2. Chamberlain SA, Garrod R, Douiri A, Masefield S, Powell P, Bucher C, et al. The impact of chronic cough: a cross-sectional European survey. Lung. 2015;193(3):401-8. doi: 10.1007/s00408-015-97012.

3. Mazzone SB, Farrell MJ. Heterogeneity of cough neurobiology: Clinical implications. Pulm Pharmacol Ther. 2019;55:62-6. doi: 10.1016/j.pupt.2019.02.002.

4. Irwin RS, Baumann MH, Bolser DC, Boulet LP, Braman SS, Brightling CE, et al. Diagnosis and management of cough executive summary: ACCP evidence-based clinical practice guidelines. Chest. 2006;129(1 Suppl):1S-23S. doi: 10.1378/chest.129.1_suppl.1S.

5. Pratter MR. Overview of common causes of chronic cough: ACCP evidence-based clinical practice guidelines. Chest. 2006;129(1 Suppl):59S-62S. doi: 10.1378/chest.129.1_suppl.59S.

6. Chamberlain S, Garrod R, Birring SS. Cough suppression therapy: does it work? Pulm Pharmacol Ther. 2013;26(5):524-7. doi: 10.1016/j.pupt.2013.03.012.

7. Vertigan AE, Theodoros DG, Winkworth AL, Gibson PG. A comparison of two approaches to the treatment of chronic cough: perceptual, acoustic, and electroglottographic outcomes. J Voice. 2008;22(5):581-9. doi: 10.1016/j.jvoice.2007.01.001.

8. Morice AH, Millqvist E, Bieksiene K, Birring SS, Dicpinigaitis P, Domingo Ribas C, et al. ERS guidelines on the diagnosis and treatment of chronic cough in adults and children. Eur Respir J. 2020;55(1). doi: 10.1183/13993003.01136-2019.

9. Morice AH, Fontana GA, Sovijarvi AR, Pistolesi M, Chung KF, Widdicombe J, et al. The diagnosis and management of chronic cough. Eur Respir J. 2004;24(3):481-92. doi:

10.1183/09031936.04.00027804.

10. Kastelik JA, Aziz I, Ojoo JC, Thompson RH, Redington AE, Morice AH. Investigation and management of chronic cough using a probability-based algorithm. Eur Respir J. 2005;25(2):235-43. doi:

10.1183/09031936.05.00140803.

11. Pratter MR, Brightling CE, Boulet LP, Irwin RS. An empiric integrative approach to the management of cough: ACCP evidence-based clinical practice guidelines. Chest. 2006;129:222S-31S. doi:

10.1378/chest.129.1_suppl.222S.

12. Irwin RS, French CL, Chang AB, Altman KW, Panel* CEC. Classification of cough as a symptom in adults and management algorithms: CHEST guideline and expert panel report. Chest. 2018;153(1):196-209. doi: 10.1016/j.chest.2017.10.016.

13. Ryan NM, Vertigan AE, Gibson PG. Chronic cough and laryngeal dysfunction improve with specific treatment of cough and paradoxical vocal fold movement. Cough. 2009;5:4. doi: 10.1186/17459974-5-4.

14. Ryan NM, Vertigan AE, Bone S, Gibson PG. Cough reflex sensitivity improves with speech language pathology management of refractory chronic cough. Cough. 2010;6(5). doi: 10.1186/1745-9974-6-5.

15. Chamberlain S, Birring SS, Garrod R. Nonpharmacological interventions for refractory chronic cough patients: systematic review. Lung. 2014;192(1):75-85. doi: 10.1007/s00408-013-9508-y. 
16. Vertigan A, Haines J, Slovarp L. An update on speech pathology management of chronic refractory cough. Journal of Allergy and Clinical Immunology: In Practice. 2019;7(6):1756-61.

17. Birring SS, Prudon B, Carr AJ, Singh SJ, Morgan MD, Pavord ID. Development of a symptom specific health status measure for patients with chronic cough: Leicester Cough Questionnaire (LCQ). Thorax. 2003;58(4):339-43.

18. Brignall K, Jayaraman B, Birring SS. Quality of life and psychosocial aspects of cough. Lung. 2008;186:S55-8. doi: 10.1007/s00408-007-9034-x.

19. Raj AA, Pavord DI, Birring SS. Clinical Cough IV:What is the Minimal Important Difference for the Leicester Cough Questionnaire? In: Chung KF, Widdicombe J, editors. Pharmacology and Therapeutics of Cough. vol 187. Berlin, Heidelberg: Springer Berlin Heidelberg; 2009. p. 311-20.

20. Hawkins M. 2017 Survey of Physician Appointment Wait Times and Medicare and Medicaid Acceptance rates. 2017.

21. Iyer VN, Lim KG. Chronic cough: an update. Mayo Clin Proc. 2013;88(10):1115-26. doi: 10.1016/j.mayocp.2013.08.007.

22. Ryan NM, Birring SS, Gibson PG. Gabapentin for refractory chronic cough: a randomised, doubleblind, placebo-controlled trial. Lancet. 2012;380(9853):1583-9. doi: 10.1016/S0140-6736(12)607764.

23. Medicare National Fee Schedule. https://www.cms.gov/Medicare/Medicare-Fee-for-ServicePayment/PhysicianFeeSched (2020). Accessed.

24. Blager FB, Gay ML, Wood RP. Voice therapy techniques adapted to treatment of habit cough: a pilot study. J Commun Disord. 1988;21(5):393-400.

25. Vertigan AE, Theodoros DG, Gibson PG, Winkworth AL. Efficacy of speech pathology management for chronic cough: a randomised placebo controlled trial of treatment efficacy. Thorax. 2006;61(12):1065-9. doi: 10.1136/thx.2006.064337.

26. Chamberlain Mitchell SA, Garrod R, Clark L, Douiri A, Parker SM, Ellis J, et al. Physiotherapy, and speech and language therapy intervention for patients with refractory chronic cough: a multicentre randomised control trial. Thorax. 2017;72(2):129-36. doi: 10.1136/thoraxjnl-2016-208843.

27. Dean BB, Gano AD, Jr., Knight K, Ofman JJ, Fass R. Effectiveness of proton pump inhibitors in nonerosive reflux disease. Clinical gastroenterology and hepatology : the official clinical practice journal of the American Gastroenterological Association. 2004;2(8):656-64. doi: 10.1016/s15423565(04)00288-5.

28. Michaudet C, Malaty J. Chronic cough: Evaluation and management. Am Fam Physician. 2017;96(9):575-80.

\section{Tables}

Table 1 Demographic and Smoking History of Participants ( $N=159)$ 


\begin{tabular}{|c|c|}
\hline Demographic and Clinical Characteristics & Frequency (\%) \\
\hline \multicolumn{2}{|l|}{ Gender } \\
\hline Female & $132(83)$ \\
\hline Male & $27(17)$ \\
\hline \multicolumn{2}{|l|}{ Age } \\
\hline $18-29$ & $4(2.5)$ \\
\hline $30-39$ & $15(9.4)$ \\
\hline $40-49$ & $20(12.6)$ \\
\hline $50-59$ & $33(20.8)$ \\
\hline $60-69$ & $50(31.4)$ \\
\hline $70-79$ & $27(17.0)$ \\
\hline $80-89$ & $6(3.8)$ \\
\hline Unreported & $4(2.5)$ \\
\hline \multicolumn{2}{|l|}{ Race/Ethnicity } \\
\hline Hispanic/Latino & $4(2.5)$ \\
\hline Black/African American & $0(0)$ \\
\hline White/Caucasian & $105(66)$ \\
\hline Native American/Native & $3(1.9)$ \\
\hline \multicolumn{2}{|l|}{ Hawaiian } \\
\hline More than 1 race & $1(0.6)$ \\
\hline Unreported / Unknown & $46(28.9)$ \\
\hline \multicolumn{2}{|l|}{ History of Smoking } \\
\hline Yes & $33(20.8)$ \\
\hline No & $122(76.7)$ \\
\hline Unreported & $4(2.5)$ \\
\hline Length of Cough & \\
\hline
\end{tabular}




\begin{tabular}{|l|l|}
\hline $2-4$ months & $18(11.3)$ \\
\hline $4-6$ months & $10(6.3)$ \\
\hline $6-12$ months & $24(15.1)$ \\
\hline $12-18$ months & $12(7.5)$ \\
\hline $18-24$ months & $12(7.5)$ \\
\hline$>24$ months & $83(52.2)$ \\
\hline
\end{tabular}

Table 2 Distribution of LCQ domain and total scores.

\begin{tabular}{|lllllll|}
\hline & Pre-BCST & & Post-BCST & & Paired t-test & \\
\hline & Mean (SD) & Range & Mean (SD) & Range & LCQ D 95\% Cl & Sig. \\
\hline Physical & $3.97(1.17)$ & $1.14-6.86$ & $5.26(1.18)$ & $1.75-7.00$ & 1.11 to 1.50 & $<.0005$ \\
\hline Psychological & $3.66(1.16)$ & $1.29-6.13$ & $5.25(1.65)$ & $1.43-7.00$ & 1.35 to 1.87 & $<.0005$ \\
\hline Social & $3.65(1.37)$ & $1.00-7.00$ & $5.41(1.59)$ & $1.00-7.00$ & 1.52 to 2.03 & $<.0005$ \\
\hline Total & $11.28(3.18)$ & $4.68-19.48$ & $15.90(4.23)$ & $4.82-21.00$ & 4.02 to 5.30 & $<.0005$ \\
\hline
\end{tabular}

$C /$ confidence interval, $L C Q$ Leicester Cough Questionnaire, $S D$ standard deviation, $D$ change

Table 3 Distribution of LCQ scores in participants who improved with BCST and those who did not improve with BCST.

\begin{tabular}{|lllllll|}
\hline & $\begin{array}{l}\text { Frequency } \\
(\%)\end{array}$ & $\begin{array}{l}\text { Mean LCQ } \\
\text { pre BCST } \\
\text { (SD) }\end{array}$ & $\begin{array}{l}\text { Mean LCQ } \\
\text { post BCST } \\
\text { (SD) }\end{array}$ & $\begin{array}{l}\text { Mean D } \\
\text { LCQ (SD) }\end{array}$ & $\begin{array}{l}\text { D LCQ } \\
\text { Range }\end{array}$ & $\begin{array}{l}\text { Enrollment to } \\
\text { follow-up (days) }\end{array}$ \\
\hline $\begin{array}{l}\text { Improved } \\
\text { (D in LCQ }\end{array}$ & $113(71.0)$ & $11.14(2.79)$ & $17.73(2.70)$ & $\begin{array}{l}6.62 \\
(3.17)\end{array}$ & $\begin{array}{l}2.00- \\
15.16\end{array}$ & $63.43(43.83)$ \\
$\begin{array}{l}\text { D 2) } \\
\text { Did not }\end{array}$ & $46(28.9)$ & $11.66(3.96)$ & $11.58(4.06)$ & -.066 & -3.14 & $65.95(43.64)$ \\
improve & & & & $(1.35)$ & -1.86 & \\
$\begin{array}{l}\text { (D in LCQ } \\
<2)\end{array}$ & & & & & & \\
\hline
\end{tabular}

LCQ Leicester Cough Questionnaire, $D$ change, $S D$ standard deviation

Table 4 Medicare HCPCS Codes Commonly Billed in Evaluation of Refractory Chronic Cough 


\begin{tabular}{|c|c|c|c|}
\hline $\begin{array}{l}\text { HCPCS } \\
\text { CODE }\end{array}$ & Medical Name & $\begin{array}{l}\text { NON-FACILITY PRICE } \\
\text { (private practice) }\end{array}$ & $\begin{array}{l}\text { FACILITY PRICE } \\
\text { (hospital) }\end{array}$ \\
\hline 31575 & Laryngoscopy without strobe & $\$ 125.95$ & $\$ 68.57$ \\
\hline 31579 & Stroboscopy & $\$ 197.05$ & $\$ 123.07$ \\
\hline 31645 & Bronchoscopy & $\$ 271.39$ & $\$ 152.66$ \\
\hline 70486 & CT Sinus & $\$ 141.47$ & $\$ 141.47$ \\
\hline 71045 & Chest X-Ray (1 view) & $\$ 25.98$ & $\$ 25.98$ \\
\hline 71046 & Chest X-Ray (2 views) & $\$ 33.20$ & $\$ 33.20$ \\
\hline 71260 & CT Chest & $\$ 199.21$ & $\$ 199.21$ \\
\hline 91038 & $\mathrm{PH} /$ Impedance Testing & $\$ 449.32$ & $\$ 449.32$ \\
\hline 92507 & Speech Therapy & $\$ 81.20$ & $\$ 81.20$ \\
\hline 92511 & Nasopharyngoscopy & $\$ 114.76$ & $\$ 38.98$ \\
\hline 92520 & Acoustic/Aerodynamic Measures & $\$ 82.28$ & $\$ 42.22$ \\
\hline 92524 & Voice Evaluation & $\$ 92.39$ & $\$ 92.39$ \\
\hline 92610 & Modified Barium Swallow Study & $\$ 89.14$ & $\$ 74.71$ \\
\hline 94010 & Spirometry & $\$ 36.09$ & $\$ 36.09$ \\
\hline 94016 & Analysis of Spirometry & $\$ 25.98$ & $\$ 25.98$ \\
\hline 94060 & Bronchodilation challenge & $\$ 60.27$ & $\$ 60.27$ \\
\hline 94200 & Included with Spirometry & $\$ 22.74$ & $\$ 22.74$ \\
\hline 94664 & $\begin{array}{l}\text { Teaching patient to use aerosol } \\
\text { generating device }\end{array}$ & $\$ 16.96$ & $\$ 16.96$ \\
\hline 94726 & Pulmonary function tests & $\$ 54.50$ & $\$ 54.50$ \\
\hline 95004 & Allergy testing (40 pricks is typical) & $\$ 4.33$ & $\$ 4.33$ \\
\hline 95012 & FENO for diagnosing asthma & $\$ 20.21$ & $\$ 20.21$ \\
\hline 95070 & Bronchoprovocation challenge & $\$ 33.56$ & $\$ 33.56$ \\
\hline 99203 & Level 3 new patient visit & $\$ 109.35$ & $\$ 77.23$ \\
\hline 99204 & Level 4 new patient visit & $\$ 167.09$ & $\$ 132.09$ \\
\hline 99205 & Level 5 new patient visit & $\$ 211.12$ & $\$ 172.51$ \\
\hline 99212 & Level 2 established patient visit & $\$ 46.19$ & $\$ 26.35$ \\
\hline 99213 & Level 3 established patient visit & $\$ 76.15$ & $\$ 52.33$ \\
\hline
\end{tabular}




$\begin{array}{llll}\mathbf{9 9 2 1 4} & \text { Level } 4 \text { established patient visit } & \$ 110.43 & \$ 80.48 \\ \mathbf{9 9 2 1 5} & \text { Level } 5 \text { established patient visit } & \$ 148.33 & \$ 113.68\end{array}$

\section{Figures}

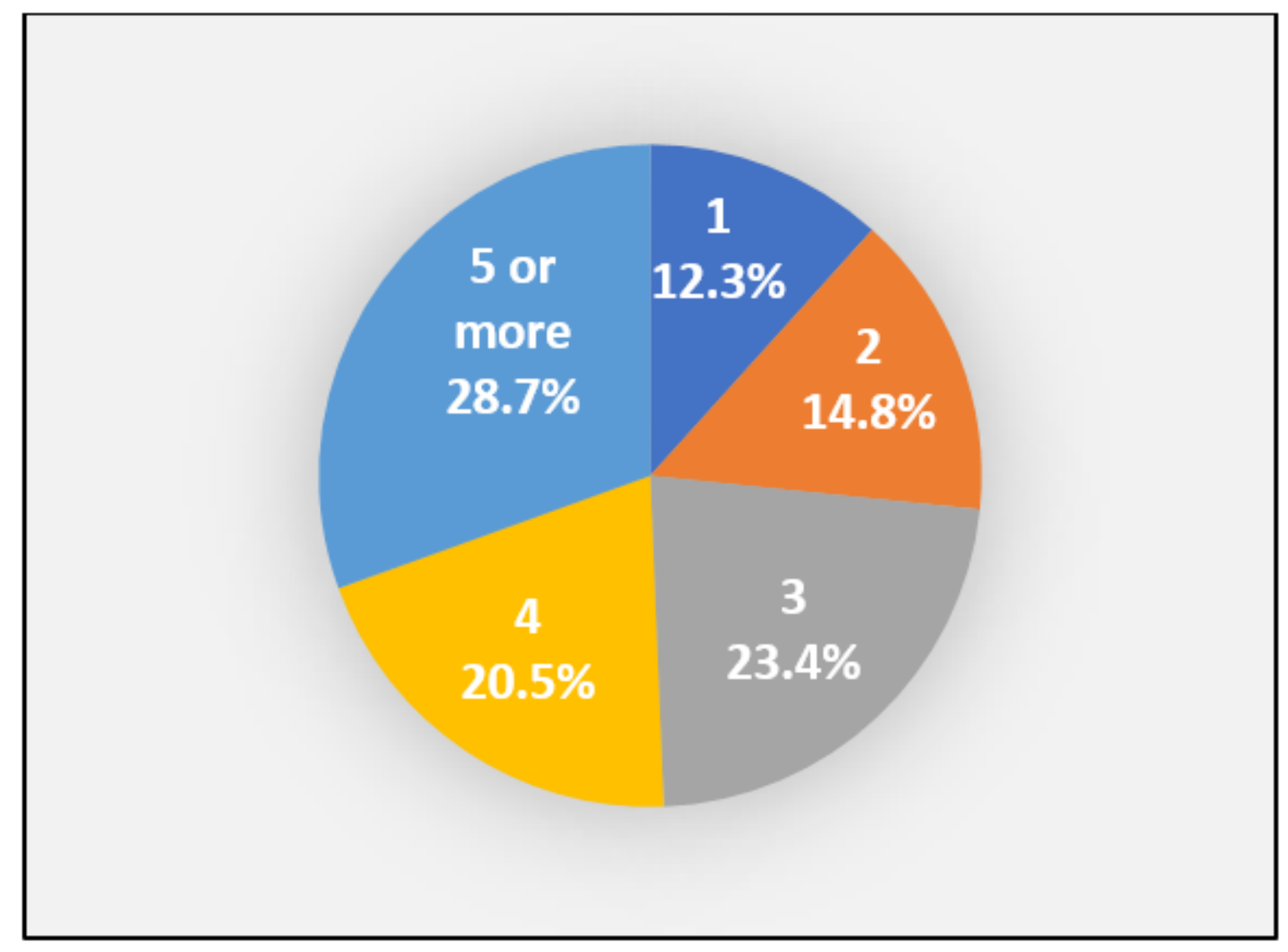

\section{Figure 1}

Distribution of physicians seen by respondents prior to BCST referral. Note: Data reflects the 122 respondents who answered the question. 


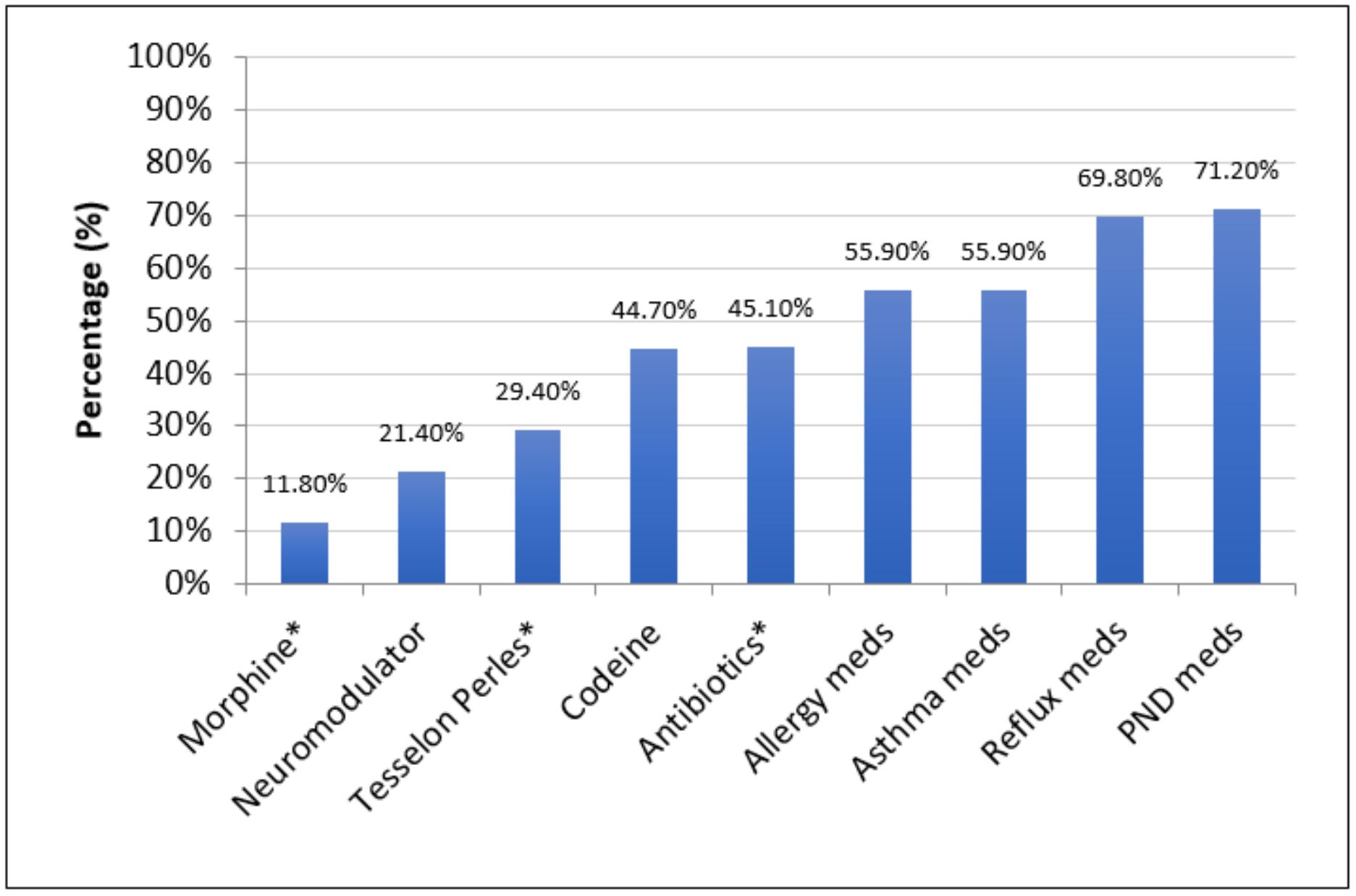

Figure 2

Medications prescribed to respondents prior to BCST referral. *Only the final survey version $(\mathrm{N}=51)$ asked about morphine, antibiotics, and Tesselon Perles. PND post nasal drip. 
Completely satisfied (cough is gone)

Very satisfied (cough is nearly gone)

Quite satisfied (Quite a bit better)

Somewhat satisfied (somewhat...

Slightly satisfied (a little better)

Not very satisfied (hardly any better)

Not at all satisfied (not any better)

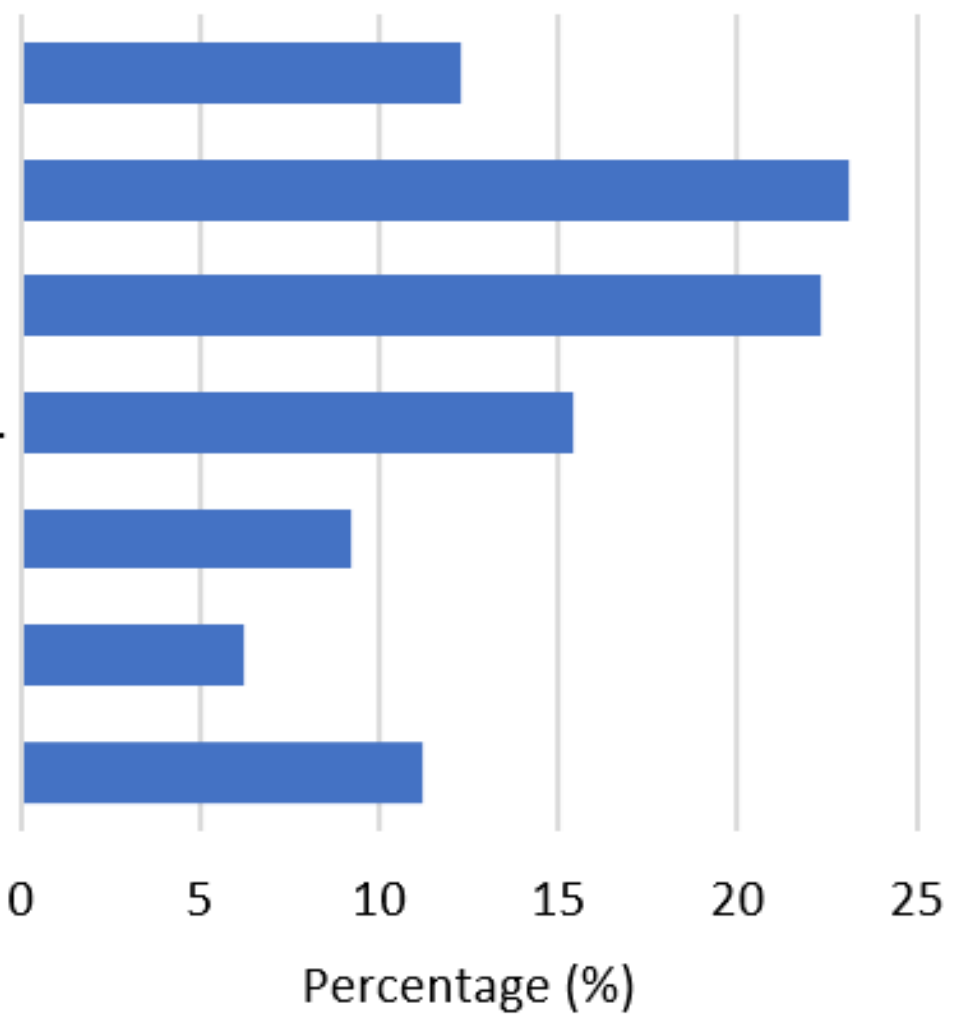

Figure 3

Distribution of satisfaction data 